\title{
Combination of PAGE and LA-ICP-MS as an analytical workflow in metallomics: state of the art, new quantification strategies, advantages and limitations
}

\author{
Alessandra Sussulini* $\dagger$ and Johanna Sabine Becker \\ Received 26th July 2011, Accepted 10th October 2011 \\ DOI: $10.1039 / \mathrm{c} 1 \mathrm{mt00116g}$ \\ Metallomics (more specifically, metalloproteomics) is an emerging field that encompasses the role, \\ uptake, transport and storage of trace metals, which are essential to preserve the functions of \\ proteins within a biological system. The current strategies for metal-binding and metalloprotein \\ analysis based on the combination of polyacrylamide gel electrophoresis (PAGE) and laser \\ ablation inductively coupled plasma mass spectrometry (LA-ICP-MS) are discussed in this review. \\ The advantages, limitations and the most recently developed and applied quantification \\ approaches for this methodology are also described.
}

\section{Introduction}

Approximately $30 \%$ of the proteins and enzymes present in a biological system contain metal or metalloid ions in their structures, and about $40 \%$ of these elements are crucial to maintaining the biological functions of proteins. ${ }^{1}$ These facts explain the increasing interest in investigations concerning metal and metalloid ions bound to proteins in biochemical, toxicological, environmental, pharmacological, and medical sciences.

Central Division of Analytical Chemistry, Forschungszentrum Jülich, D-52425, Jülich, Germany.E-mail: a.sussulini@fz-juelich.de

$\dagger$ Alexander von Humboldt Foundation postdoc fellow.
In recent years, novel improvements regarding analytical instrumentation and methodologies have significantly enhanced abilities to identify, localize and quantify metals and metalloids bound to proteins, leading to the development of metallomics as a research field. ${ }^{2-7}$

Metallomics is defined as the comprehensive analysis of the entirety of metal and metalloid species within a cell or tissue type. ${ }^{6}$ If the emphasis is on metal or metalloid-protein complexes, the term metalloproteomics is used. ${ }^{2}$ One of the analytical strategies applied in metalloproteomics consists in first separating proteins from a sample of interest and then combining atomic spectrometry for the detection of metals or metalloids bound to proteins with biomolecular mass spectrometry (MALDI-, ESI- or FTICR-MS)

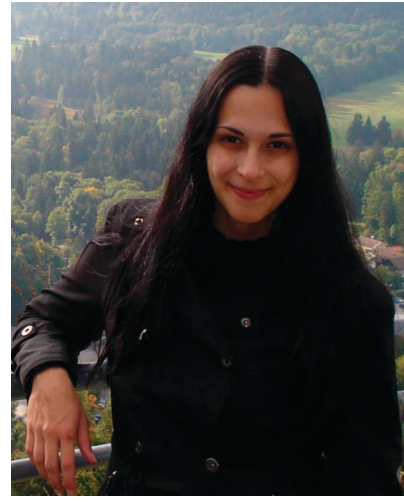

Alessandra Sussulini
Dr Alessandra Sussulini received her PhD in Analytical chemistry from the State University of Campinas, Brazil. At the moment, she is a postdoctoral fellow from the Alexander von Humboldt Foundation at the BrainMet (Bioimaging of Metals in Brain and Metallomics) laboratory at the Central Division of Analytical Chemistry, Forschungszentrum Jülich, Germany. Her present research activities are focused on the application of LA-ICP-MS to brain samples and the development of laser microdissection (LMD)-ICP-MS. She has also experience in molecular mass spectrometry (MALDI-, SELDIand ESI-MS), protein separation methods (PAGE and UPLC) and atomic absorption spectrometry (FAAS and ETAAS).

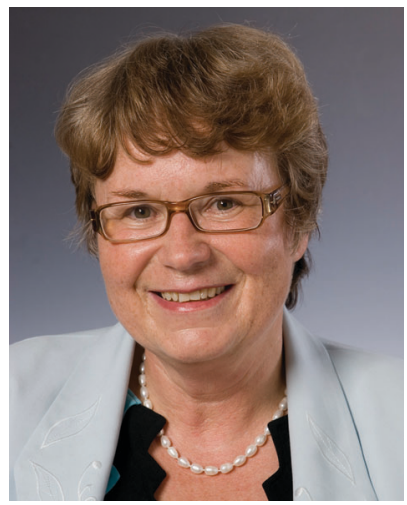

Johanna Sabine Becker
Dr habil. J. Sabine Becker is the head of the BrainMet (Bioimaging of Metals in Brain and Metallomics, www. brainmet.com) Centre of Excellence at Forschungszentrum Jülich, Germany. She has pioneered quantitative imaging LA-ICP-MS (including near field $L A$ and laser microdissection ICP-MS) of elements at $\mu \mathrm{m}$ to $\mathrm{nm}$ scale for brain research and metallomics. Dr Becker is the author of the comprehensive handbook: Inorganic Mass Spectrometry: Principles and Applications, Wiley, 2007, of 330 scientific publications, 24 patents, is a IUPAC Fellow and member of several Editorial/Advisory Boards of the Int. J. Mass Spectrom., J. Anal. At. Spectrom., Talanta, Metallomics and others. 


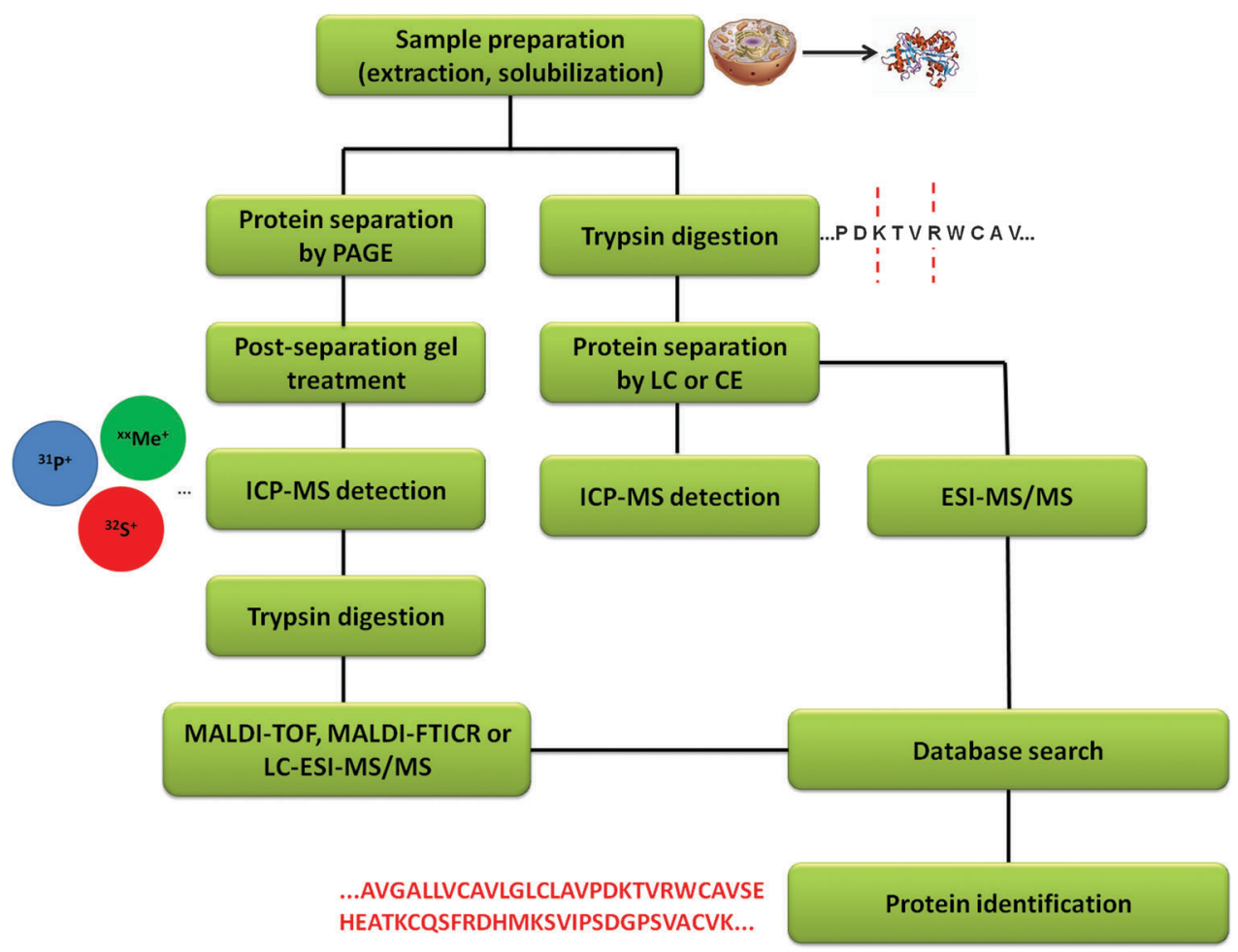

Fig. 1 Illustrative diagram of the analytical steps necessary to obtain comprehensive metalloproteomics information.

for the elucidation of the structure, dynamics and functions of metal-protein complexes. ${ }^{7}$ Protein separation can be carried out by capillary electrophoresis (CE), liquid chromatography (HPLC) or polyacrylamide gel electrophoresis (PAGE). This review focuses on the latter since it is a key platform for high-resolution protein separation. Fig. 1 shows a diagram illustrating the analytical steps necessary to obtain comprehensive metalloproteomics information about a biological system.

In the first review describing the combination of gel electrophoresis with atomic spectrometry techniques for the detection of trace elements bound to proteins, published in 2004 by McLeod's working group, ${ }^{8}$ inductively coupled plasma mass spectrometry (ICP-MS) was the analytical technique selected in $43 \%$ of the publications. As shown in Fig. 2, it can be seen that the use of ICP-MS has been rising in the last seven years due to characteristics such as multielement capability, high sensitivity and possibility of measuring isotope ratios, at the expense of other techniques such as X-ray, atomic absorption spectrometry (AAS) or atomic fluorescence spectrometry (AFS).

Elemental mass spectrometry via laser ablation (LA) coupled to ICP-MS can be employed for the analysis of solid samples (such as dried electrophoresis gels), with spatial resolution usually in the 110-4 $\mu \mathrm{m}$ range (depending on the laser ablation system used), providing accurate sampling of small volumes or amounts of sample. ${ }^{6}$ This technique has been used for quantitative mass spectrometric imaging (MSI) of elements in several biological (e.g., study of neurodegenerative diseases in brain samples) and environmental (e.g., accumulation of essential elements in leaves) applications, as reviewed in a recently published textbook and several reviews. ${ }^{9-12}$

The main purpose of the present review is to describe and compare different methodologies using PAGE combined with

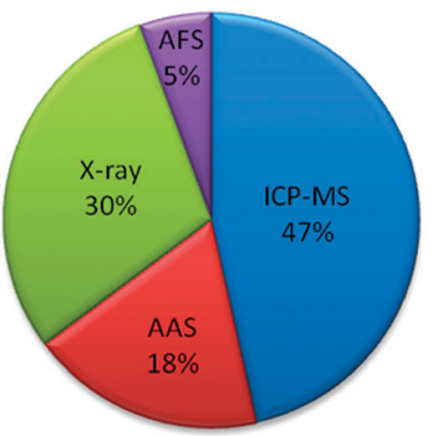

Fig. 2 Present percentage of metallomics studies using gel electrophoresis combined with atomic spectrometry detection techniques. Based on Thomson Reuters Web of Knowledge ${ }^{48}$ search.

LA-ICP-MS, then point out their limitations (originating from the preservation of the integrity of metal-protein bond and contamination issues) and indicate possible solutions in order to achieve reliable quantitative results in metalloproteomics research. The most recently developed approaches for the quantification of proteins, including metal-binding and metalloproteins, based on species-specific isotope dilution analysis and chemical labeling are also discussed.

\section{Polyacrylamide gel electrophoresis as a protein separation method}

Polyacrylamide gel electrophoresis (PAGE) is undoubtedly the most extensively used protein separation method because of its high resolving power and good reproducibility. It can be employed to separate proteins according only to their molar 
masses (1-D PAGE) or it may be combined with isoelectric focusing (IEF) and can then also separate proteins according to their isoelectric point ( $\mathrm{pI}$ ), thus generating a two-dimensional electropherogram (2-D PAGE).

PAGE can be classified as denaturing or native PAGE. ${ }^{13}$ In the case of denaturing PAGE, the anionic surfactant sodium dodecyl sulfate (SDS) and a reducing agent, such as dithiothreitol (DTT) or $\beta$-mercaptoethanol, are employed in order to disrupt both non-covalently bound protein complexes and aggregates into a solution of individual polypeptides, providing a gel with a very good resolution. ${ }^{14}$ In the case of native (also called nondenaturing) PAGE, protein complexes with a high molar mass can be separated and their tertiary structures are maintained during the electrophoretic process, but the resolution is damaged because the native proteins cannot move as fast as an individual (denatured) protein. Native PAGE can be performed in different ways, for example: blue native (BN)-PAGE employs Coomassie Brilliant Blue dye to provide the necessary charges to the protein complexes for electrophoretic separation and anodal native (AN)-PAGE uses a basic buffer system, which is applicable for the analysis of proteins with $\mathrm{pI}$ lower than approximately 8.5.

Despite all the advantages of PAGE for protein separation, it must be remembered that this technique, as well as all the reagents and buffers used in gel processing, was not originally designed for trace or ultratrace element analysis. ${ }^{8,15}$ Some limitations therefore have to be considered when applying PAGE as a protein separation method before the detection and quantification of bound elements. These limitations will be discussed in the following sections, as well as the most recently proposed methodologies for performing the challenging quantification of proteins by combining PAGE with LA-ICP-MS.

\section{LA-ICP-MS: instrumentation and experimental procedures}

As metals and metalloids bound to proteins are present in very low concentrations, an extremely sensitive and selective detector needs to be applied for their identification and quantification. ICP-MS fulfills these requirements, due to its particular characteristics: (i) high analytical throughput, (ii) low detection limits for most elements, (iii) minimal matrix effects, (iv) specific response for the heteroatoms (metals, metalloids or nonmetals), (v) capability of up to 8 orders of magnitude of linear dynamic range, (vi) information about isotope ratios that can be applied for exact and precise (metallo)protein quantification using isotope dilution analysis, and (vii) simple coupling to different separation methods. ${ }^{2,16}$ However, since the strong ionization of the sample in the plasma source causes the loss of structural information about the proteins, this feature should be provided by molecular mass spectrometry using softer ionization sources (MALDI or ESI). Therefore, only with the combination of elemental and molecular mass spectrometry techniques is it possible to obtain global metalloproteomic information for a biological system. ${ }^{7}$

After PAGE separation, the protein bands or spots can be analyzed by ICP-MS in two ways: (i) as a solution, where prior microwave-assisted digestion of the gel spots is performed and the resulting solution is inserted into the nebulizer of the equipment or (ii) in situ, where the gel is directly analyzed using laser ablation (LA)-ICP-MS. ${ }^{2,17,18}$ The first method is more time-consuming and susceptible to sample contamination and/or losses than the second using $\mathrm{LA},{ }^{2}$ which is the focus of this review.

LA-ICP-MS is a powerful microanalytical technique that uses a focused laser beam (Nd:YAG, excimer) to ablate material from the surface of a solid sample. The sample is mounted on a sample holder in the laser ablation chamber. The photons of the laser beam interact within the laser spot with the material that is ablated and transported by a continuous flow of argon (usually helium may be mixed with argon before the torch injector) to the ICP source. ${ }^{7,19}$ The ions formed are extracted from the atmospheric ion source and subsequently analyzed in the mass spectrometer (quadrupole or time-of-flight mass analyzer, or double-focusing sector field mass spectrometer). For more details on LA-ICP-MS instrumentation, see the textbook on "Inorganic Mass Spectrometry, Principles and Applications" by J. S. Becker. ${ }^{9}$ Detection of elements bound to proteins by LA-ICP-MS is fast and fairly robust, as no further reaction or derivatization step is involved, and the signal is, theoretically, directly proportional to the amount of the element present in the protein spot. ${ }^{6,20}$

There are three ablation strategies for element detection by LA-ICP-MS in proteins separated by gel electrophoresis: (i) microlocal analysis of the spots, ${ }^{17}$ (ii) line scan through the spots $^{21}$ and (iii) imaging of gel. ${ }^{18,22,23}$ The difference between these strategies for LA-ICP-MS analysis consists in the time required: while imaging is more time-consuming (for example, about 12 hours for a gel region of $3 \mathrm{~cm}^{2}$ with a resolution of $110 \mu \mathrm{m}$ using $150 \mu \mathrm{m} \mathrm{s}^{-1}$ scan speed and distance between the lines of $30 \mu \mathrm{m}$ ), the microlocal analysis of the spots is faster (about 30 seconds to analyze an individual protein spot). ${ }^{24}$ On the other hand, the imaging mode has the advantage of allowing the visualization of element distribution along the proteins contained in a gel region and staining of the gel for protein location can be avoided (see Section 4). The limitation of microlocal analysis of the spots by LA-ICP-MS is that ambiguous signal spikes commonly occur and the identification of these disturbances can be difficult. ${ }^{15}$ In the line scan mode, the drawback is that dust particles containing elements such as copper, zinc, manganese and aluminium often appear like well-resolved sharp protein bands, so that the signals from contaminants must be distinguished from the protein-bound metal. To overcome these problems, it is suggested that the imaging mode be used to verify the presence of elements bound to proteins, even though it is more time-consuming.

The main parameters that have to be optimized in LA-ICP-MS when gels are the material to be ablated are the same as for the other types of samples, such as laser spot size, repetition frequency and scan speed in the case of line scan or imaging analysis. The laser wavelength is instrumental-defined, mostly $\mathrm{Nd}$ :YAG lasers are used with a wavelength of 266 or $213 \mathrm{~nm}$. About the laser pulse length, ns lasers can easily ablate soft matters as tissues, but also ps and fs lasers can be employed. The detection/quantification of metals/metalloids bound to proteins is not specifically influenced by these parameters, since ICP-MS is not a molecule-specific detector, but they have a direct influence on the ablation efficiency and consequently on the sensitivity of the measurement. ${ }^{9}$

A general schematic analytical workflow for PAGE combined with LA-ICP-MS in metalloproteomics is shown in Fig. 3. 


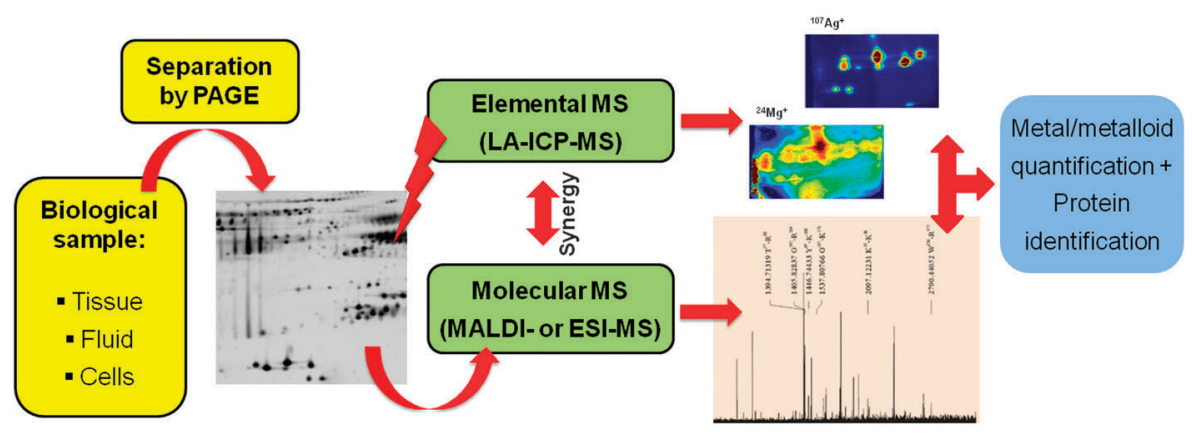

Fig. 3 Schematic workflow for PAGE combined with LA-ICP-MS experimental methodology.

Though many applications of this methodology are described in the recent literature, some limitations in applying this strategy for the quantification of elements bound to proteins have been pointed out by different authors ${ }^{2,15,16,25}$ and they will be further discussed in the next section.

\section{Applications, limitations and possible solutions}

A selection of the most interesting applications of PAGE combined with LA-ICP-MS for biological samples can be found in Table 1, and others will be described in more detail in this section.

Systematic studies concerning the fundamental conditions for an effective application of PAGE combined with LA-ICP-MS methodology for the identification and quantification of metalbinding and metalloproteins are still scarce in the literature. ${ }^{15}$ The critical points that need to be considered when this methodology is applied in metalloproteomics studies are discussed in the following, especially if the analyte of interest (metal-binding or metalloprotein) has a weak metal-protein bond.

\subsection{Preservation of the integrity of metal-protein bond}

It is well established that the most significant limitation in the use of PAGE techniques for the separation of proteins before the identification and quantification of bound elements by LA-ICP-MS concerns the preservation of the metal-protein bond. Potential metal losses are influenced by the affinity between the metal and a given protein. As an example, $\mathrm{Cu}^{2+}$, $\mathrm{Fe}^{2+}, \mathrm{Mn}^{2+}$ and $\mathrm{Mo}^{2+}$ have the strongest coordinating interactions with proteins due to their features (e.g., small atomic radius and interactions via electrostatic forces). In fact, weakly (non-covalently) bound metals, as in the case of metalbinding proteins, are more easily lost during sample preparation and electrophoretic process than those covalently bound, as in the case of metalloproteins. ${ }^{2}$ Many complexes are labile and can be destroyed by exchange with metal impurities of the gel, and metal losses can take place during protein separation, especially considering metal-binding proteins and the use of denaturing processes (SDS-PAGE and 2-D PAGE). ${ }^{13,20}$ The influence of the nature and conditions of the electrophoretic process, as well as of gel staining and drying, on metal-protein bond maintenance will be discussed in the following.

4.1.1. Native versus denaturing electrophoresis. Nondenaturing PAGE has been explored as an alternative in order to solve the problem of metal-protein bond preservation, since the tertiary structure of the proteins is conserved during separation. As shown in the literature, Becker et al. ${ }^{26}$ detected and quantified a variety of metals (copper, zinc, iron, nickel, chromium, cadmium, and lead) in metal-binding proteins present in rat liver and kidney by using BN-PAGE to separate

Table 1 Applications of PAGE combined with LA-ICP-MS for biological samples (more applications are described in detail in Section 4)

\begin{tabular}{|c|c|c|c|c|c|}
\hline Sample & $\begin{array}{l}\text { PAGE } \\
\text { technique }\end{array}$ & Equipment & Element(s) detected & Results & Reference \\
\hline$\overline{\text { Slug tissue }}$ & BN-PAGE & $\begin{array}{l}\text { LA-ICP-SFMS and } \\
\text { MALDI-TOFMS }\end{array}$ & $\mathrm{Zn}$ & $\begin{array}{l}\text { Zn-containing proteins in the digestive } \\
\text { gland }\end{array}$ & Becker et al. $^{40}$ \\
\hline $\begin{array}{l}\text { African catfish } \\
\text { organs }\end{array}$ & SDS-PAGE & LA-ICP-SFMS & $\mathrm{Se}$ & High accumulation of Se in the kidney & Pedrero et l. $^{41}$ \\
\hline $\begin{array}{l}\text { Elsholtzia splendens } \\
\text { roots }\end{array}$ & 2-D PAGE & $\begin{array}{l}\text { LA-ICP-QMS and } \\
\text { LC-ESI-ITMS }\end{array}$ & $\begin{array}{l}\mathrm{Cu}, \mathrm{Zn}, \mathrm{Na}, \mathrm{Mg}, \mathrm{K}, \\
\mathrm{Ca}, \mathrm{Mn}, \mathrm{Fe}, \mathrm{P}, \mathrm{S}\end{array}$ & $\mathrm{Cu}$ and $\mathrm{Zn}$ enrichment after $\mathrm{Cu}$ treatment & Wu et al. ${ }^{42}$ \\
\hline $\begin{array}{l}\text { Human serum and } \\
\text { tau protein }\end{array}$ & 2-D PAGE & $\begin{array}{l}\text { LA-ICP-SFMS and } \\
\text { MALDI-FTICRMS }\end{array}$ & $\mathrm{P}$ & Hyperphosphorylation of tau protein & Becker et al. ${ }^{43}$ \\
\hline Rat kidney & $\begin{array}{l}\text { IEF and 2-D } \\
\text { PAGE }\end{array}$ & LA-ICP-QMS & $\mathrm{U}$ & $\mathrm{U}$ is not covalently bound to proteins & Frelon et al. ${ }^{44}$ \\
\hline Human plasma & SDS-PAGE & $\begin{array}{l}\text { LA-ICP-QMS and } \\
\text { LC-ESI-ITMS }\end{array}$ & $\mathrm{Se}$ & Characterization of $\operatorname{SelP}^{a}$ and $\mathrm{GPx}^{b}$ & Ballihaut et al. ${ }^{31}$ \\
\hline $\begin{array}{l}\text { Yeast mitochondrial } \\
\text { membrane }\end{array}$ & $\begin{array}{l}\mathrm{BN} / \\
\mathrm{SDS}-\mathrm{PAGE}\end{array}$ & $\begin{array}{l}\text { LA-ICP-SFMS and } \\
\text { MALDI-FTICRMS }\end{array}$ & $\mathrm{P}, \mathrm{Cu}, \mathrm{Zn}, \mathrm{Fe}$ & Phosphorylated ATPase subunits & $\begin{array}{l}\text { Krause- } \\
\text { Buchholz et al. }{ }^{45}\end{array}$ \\
\hline Escherichia coli & SDS-PAGE & LA-ICP-QMS & $\mathrm{S}, \mathrm{Zn}, \mathrm{Cd}$ & $\begin{array}{l}\text { Induction of protein } \mathrm{SmtA} \text { synthesis } \\
\text { by } \mathrm{Zn} \text { and binding of } \mathrm{Zn} \text { and } \mathrm{Cd}\end{array}$ & Binet et al. ${ }^{46}$ \\
\hline Human brain & 2-D PAGE & $\begin{array}{l}\text { LA-ICP-SFMS and } \\
\text { MALDI-FTICRMS }\end{array}$ & $\mathrm{P}, \mathrm{S}, \mathrm{Cu}, \mathrm{Fe}, \mathrm{Zn}$ & $\begin{array}{l}\text { Determination of degree of phosphorylation } \\
\text { and metal concentration }\end{array}$ & Becker et al. ${ }^{47}$ \\
\hline
\end{tabular}


proteins prior to LA-ICP-MS element detection and protein identification by MALDI-TOF MS. Some of the identified proteins (cathepsin B precursor and FAM44B) are not described in protein databanks as metalloproteins, which indicates that the quantified metals were not covalently bound and could have been lost if denaturing PAGE had been used instead of blue native (BN)-PAGE.

However, the use of a non-denaturing PAGE technique is not sufficient to guarantee metal-protein binding preservation, as other components of the buffers can readily complex metals, disturbing the equilibrium between bound and unbound species. $^{2}$

Another limitation of native PAGE concerns resolution, i.e., the ability to distinguish between two neighboring spots or lines of the same element or isotope, which is one of the main parameters for the successful determination of metals bound to proteins by PAGE combined with LA-ICP-MS methodology. ${ }^{15}$ Even if the possibility of a two-dimensional non-denaturing electrophoresis procedure (2-D BN-PAGE) is considered, as described by J. Su. Becker et al., ${ }^{22}$ the resolution of the protein separation remains a problem and, as a consequence, the analysis of isoforms or post-translational modified proteins is not possible. In this way, 2-D PAGE should not be completely discarded as an option for protein separation prior to the detection and quantification of elements by LA-ICP-MS, since not all proteins in a biological system are susceptible to having their elemental bonds broken during PAGE, owing to their different metal-protein bond stabilities. This may explain the success of several studies on the analysis of metalloproteins, even if denaturing conditions for separation were employed. ${ }^{2}$ One example is a recent study ${ }^{24}$ where human blood serum proteins from healthy individuals and from bipolar disorder patients treated either with or without using lithium were separated by 2-D PAGE, identified by MALDI-TOF MS/ MS and the bound metals were detected by LA-ICP-MS. A differential profile in terms of metals (sodium, magnesium, zinc, calcium and iron) bound to serum proteins for all the studied groups was observed, hence opening the door for further studies on the discovery of potential biomarkers for bipolar disorder and its treatment with lithium.

Another example showing the applicability of 2-D PAGE for the analysis of metalloproteins that remain stable during the denaturing process is described by $\mathrm{J}$. Su. Becker et $a l^{27}$ Isotopic-enriched tracers $\left({ }^{54} \mathrm{Fe},{ }^{65} \mathrm{Cu}\right.$, and $\left.{ }^{67} \mathrm{Zn}\right)$ doped to brain proteins from Alzheimer disease patients after separation by 2-D PAGE were used in order to study the formation of proteins containing copper, zinc and iron in a human brain sample. The protein spots were screened by LA-ICP-MS with respect to these metal ion intensities. ${ }^{54} \mathrm{Fe} /{ }^{56} \mathrm{Fe},{ }^{65} \mathrm{Cu} /{ }^{63} \mathrm{Cu}$ and ${ }^{67} \mathrm{Zn} /{ }^{64} \mathrm{Zn}$ isotope ratios in metal-containing proteins were measured by LA-ICP-MS and the protein identification was performed by high-resolution MALDI-FTICR-MS. The isotope ratio measurements obtained by LA-ICP-MS indicated certain protein spots with a natural isotope composition of copper, zinc and/or iron. These proteins already contained the investigated metals in their structures and were shown to be stable enough to remain in the reducing conditions during gel electrophoresis.

In summary the use of non-denaturing (native) PAGE can provide an improved preservation of metal-protein bonds in relation to denaturing processes, but it cannot offer good resolution for protein separation. When analyzing complex samples where a high diversity of proteins and resolution is required, denaturing PAGE (more specifically, 2-D PAGE) should be employed, although it is necessary to consider the analysis of only those elements strongly bound to proteins.

4.1.2. Conditions of the electrophoresis process. Other factors that can interfere with maintenance of the metal-protein bond are the conditions of the electrophoresis process, more specifically, the type of trailing ion and the intensity of applied current. This can be exemplified by the work of Jiménez et al., ${ }^{13}$ where two metal-binding proteins with distinct metal-protein affinities were analyzed: alcohol dehydrogenase (ADH), a metal-binding protein containing zinc, and superoxide dismutase (SOD), a metalloprotein containing copper and zinc. The authors compared denaturing and non-denaturing PAGE methods for the separation of the proteins, as well as the use of glycine or tricine as trailing ions. Quantitative detection of copper and zinc in SOD was performed using either denaturing or non-denaturing PAGE followed by LA-ICP-MS analysis. On the other hand, the determination of zinc in ADH by LA-ICP-MS depended on the nature of the PAGE method, since it could only be quantified by using native PAGE. When tricine was used as the trailing ion instead of glycine in denaturing PAGE, better quantitative results were obtained for copper and zinc in SOD. This can be explained by the fact that tricine has a lower affinity for copper and zinc than glycine and the metal-protein binding can be preserved due to a slower movement of the proteins during the electrophoretic procedure at usual $\mathrm{pH}$ values. ${ }^{13}$

Another important point to consider is the intensity of the current applied in the electrophoretic process. ${ }^{13}$ The authors point out that as higher current is applied, even using tricine as the trailing ion, the possibility of metal-protein binding losses is also higher because the proteins advance faster during the electrophoresis process.

In summary, soft conditions (low applied current and use of tricine, which causes less protein movement, as trailing ion) are recommended for the electrophoresis process in order to preserve metal-protein binding.

4.1.3. Gel staining. After gel electrophoresis separation, the proteins can be visualized and located in the gel by using a staining procedure. Nevertheless, this is considered to be a source of losses from metals bound to proteins, as it alters the stability of the metal-protein complexes. ${ }^{13}$ It was previously demonstrated ${ }^{15}$ that the use of either Coomassie blue or silver can cause such problems, although it is not so relevant in the case of covalently bound heteroelements, such as selenium. When bovine serum albumin and element-doped gels were exposed for $1 \mathrm{~h}$ in $5 \%(\mathrm{v} / \mathrm{v})$ phosphoric acid, used in the Coomassie blue staining protocol, an element loss of up to $90 \%$ was found and when the gels were exposed to $2.5 \%$ (m/v) sodium carbonate, employed in the silver staining procedure, this resulted in an element loss of up to $57 \% .^{15}$

Therefore, the potential solutions for problems related to gel staining are: (i) avoid staining and use the total ablation of the gel (imaging mode) in LA-ICP-MS analysis, (ii) run the samples in duplicate on two halves of a single gel, one half 
Table 2 Limitations and proposed solutions for PAGE combined with LA-ICP-MS methodology, updated from a previous review ${ }^{2}$

\begin{tabular}{|c|c|}
\hline Limitation & Suggestions \\
\hline $\begin{array}{l}\text { Preservation of the integrity of metal-protein bond during } \\
\text { PAGE separation }\end{array}$ & $\begin{array}{l}\text { Use of non-denaturing PAGE, substituting glycine for tricine as trailing ion, }{ }^{13} \\
\text { applying lower current in the electrophoresis process }{ }^{13} \text { or considering analysis } \\
\text { of only elements strongly bound to proteins }\end{array}$ \\
\hline $\begin{array}{l}\text { Reproducibility of 2-D PAGE compromises use for } \\
\text { quantitative purposes }\end{array}$ & Running the gels in the same chamber can reduce this problem \\
\hline Staining of gels causes metal losses & $\begin{array}{l}\text { Use of imaging mode }{ }^{18,22} \text { of LA-ICP-MS in an unstained gel, }{ }^{15} \text { running } \\
\text { samples in duplicate in the same } 1 \text {-D gel and staining just one half of the gel }{ }^{15} \\
\text { or considering the analysis of only elements strongly bound to proteins }\end{array}$ \\
\hline Gel drying can cause metal losses & $\begin{array}{l}\text { Incubation of the gel with glycerol before drying }{ }^{15} \text { or blotting the gels onto a } \\
\text { membrane } 15,28\end{array}$ \\
\hline Phosphorus contamination in & Adding a washing step after the blotting process with $\mathrm{Ga}\left(\mathrm{NO}_{3}\right)_{3}{ }^{32}$ \\
\hline Reagents and buffers may be contaminated with trace elements & $\begin{array}{l}\text { Use of high-purity reagents and clean room facilities or blotting the gels onto a } \\
\text { membrane }{ }^{15,28}\end{array}$ \\
\hline $\begin{array}{l}\text { Lack of certified and commercially available metalloprotein or } \\
\text { metal-binding protein standards for protein quantification }\end{array}$ & $\begin{array}{l}\text { Use of SS-IDA, }{ }^{34} \text { chemical labeling, }{ }^{28,36} \text { natural (hetero)element tags }{ }^{35} \text { or } \\
\text { external calibration methods }\end{array}$ \\
\hline
\end{tabular}

stained for protein visualization and the other half only for ablation (feasible just for 1-D gels), or (iii) assume that metal ions are, to a certain extent, lost during staining of the gel (analysis of only covalently bound elements). ${ }^{2,15}$

4.1.4. Gel drying. Before LA-ICP-MS measurements, the gel has to be dried. After separation, polyacrylamide gels contain about $65 \%$ of removable water and if the wet gel is placed in the laser ablation chamber, the water content will continually evaporate during the analysis. This results in irregular drying and the appearance of cracks that obstruct the ablation of the gel. ${ }^{15}$ The most common procedures for performing gel drying are: (i) drying the gel between glass plates, (ii) use of a cryo-cell for ablation, (iii) wrapping the gel, and (iv) completely drying the gel using a gel dryer.

Raab et al. ${ }^{15}$ tested wrapping and complete drying of the gel and found the highest sensitivities with the lowest relative standard deviations (RSDs) for the unpacked gel. The authors also tested different solutions (glycerol, water, methanol, acetonitrile) for incubating the gel before drying. Glycerol incubation proved to be a suitable method for drying, without extensive element losses, considering that protein-bound elements remain bound to the protein after PAGE separation.

An alternative approach for post-separation treatment before LA-ICP-MS analysis that eliminates the need for gel drying is blotting the separated proteins onto a suitable membrane (electroblotting) ${ }^{15,28}$ or eluting the separated proteins online $e^{29}$ or offline, ${ }^{30}$ thus avoiding the problem of gel stabilization. Electroblotting consists in the transfer from gels to membranes, concentrating proteins at the surface of an immobilizing polymer substrate, such as polyvinylidene fluoride (PVDF) or nitrocellulose (NC) membrane, after PAGE. ${ }^{31}$ Although this is a promising sample preparation method for LA-ICP-MS analysis, low protein transfer efficiency onto membranes and contaminations (discussed in the next item) are the limiting factors.

In summary, the recommendations for avoiding metal losses in the gel drying procedure before LA-ICP-MS analysis are to incubate the gel with glycerol prior to drying or blot the gels onto a membrane.

\subsection{Contamination}

As metals and metalloids bound to proteins occur naturally at very low concentrations, possible sources of contamination must be avoided. As mentioned in Section 2, PAGE techniques were not originally designed for trace or ultratrace element analysis. Thus, reagents and buffers used for protein extraction or gel preparation and running may be contaminated with trace elements. It is extremely important to use high-purity (and highquality) reagents during all steps of the analysis and, if available, to make use of clean room facilities.

Electroblotting of the gels in a membrane is a good alternative avoiding contamination problems. However, phosphorus contained in the membranes can cause a different type of contamination. A way to overcome this problem was proposed by Wind et al., ${ }^{32}$ where a washing step with $\mathrm{Ga}\left(\mathrm{NO}_{3}\right)_{3}$ as a complexing agent was included to remove any non-covalently bound phosphate from the membrane.

Table 2 summarizes the main limitations and proposed solutions for PAGE combined with LA-ICP-MS methodology discussed in this section.

\section{Novel potential strategies for quantification of proteins by combining PAGE with LA-ICP-MS}

Quantification of metalloproteins and metal-binding proteins by PAGE combined with LA-ICP-MS methodology is not a trivial task. Since there is a lack of certified and commercially available metalloprotein or metal-binding protein standards, most of the current calibration methods consist in the use of metal-spiked gels or the introduction of a standard metal solution into the ablation chamber.

Recently, Pozebon et al. $^{33}$ developed a solution-based calibration method where the dry aerosol produced by laser ablation of the solid sample and the wet aerosol generated by pneumatic nebulization of aqueous standards are carried by two separated flows of argon and directly introduced into the injector tube through two different apertures in a special ICP torch, and are then mixed in the plasma. The authors found that the proposed wet plasma condition provided enhanced sensitivity and a linear correlation coefficient of calibration curves in comparison to dry plasma conditions (ablation of solid material only). Differences in the sampling rate and aerosol transport efficiency occur when the laser ablation of solid samples and simultaneous nebulization of aqueous standards are performed and it is known that water alters 
the fundamental proprieties of the plasma. Although solutionbased calibration can provide improved sensitivity and linearity, it is necessary to be aware of interferences caused by polyatomic ions, since their formation rate increases in the presence of water. This strategy was shown to be efficient, but as yet it has only been applied for brain tissue imaging and the application for PAGE combined with LA-ICP-MS methodology should be a further step. Although such external calibration methods are easy to operate and the aqueous element standards are widely available, they neither consider the behavior of the proteins during the electrophoretic process, nor compensate for effects in a protein spot or band, particularly the two-dimensional distribution of the spot. ${ }^{34}$ Hence, the emphasis in this review is on quantification methods that take protein behavior into account.

Natural (hetero)element tags (covalently bound elements such as sulfur, selenium, iodine or phosphorus) can also be used for (metallo)protein quantification, as is described in a critical review by Prange and Pröfrock. ${ }^{35}$ However, this approach is restricted to the analysis of proteins containing such elements.

Sulfur is present in proteins in cysteine and methionine residues. As these amino acids occur with a cumulative abundance of $5 \%$ in natural peptides, statistically, at least one sulfur-containing amino acid is expected to occur in every polypeptide with a length of at least 20 amino acids. Phosphorus is present in proteins in serine, threonine and tyrosine residues. Up to $30 \%$ of all proteins in a eukaryotic cell are assumed to be phosphorylated and this is one of the most important post-translational modifications of a protein, which is responsible for biological functions such as cell signaling and enzymatic activity. When the amino acid sequence of a protein is identified by molecular mass spectrometry (MALDI-, ESI-, FTICR-MS), the absolute amount of a protein can be obtained by sulfur or phosphorus determination via ICP-MS. Sulfur is preferred as an internal standard for quantification instead of other naturally existing elements in proteins because of its high abundance. ${ }^{2,35}$ Some examples of the use of natural element tags for quantification are shown in Table 1 (see ref. 41, 44 and 45).

Even though many proteins or peptides present in a biological system contain sulfur and/or phosphorus, when ICP-MS is used for their detection/quantification, it is necessary to consider some difficulties regarding polyatomic interferences. This problem can be reduced by the use of a collision/reaction cell, which is a device that removes interfering ions through ion/neutral reactions. ${ }^{35}$

The use of natural element tags is already a well-established approach for the quantification of (metallo)proteins that contain such elements in their structures. However, the focus of the present review is on new strategies for the quantification of proteins (including metal-binding and metalloproteins) using PAGE combined with LA-ICP-MS methodology. Therefore, two strategies developed in the last three years are described below.

\subsection{Species-specific isotope dilution analysis (SS-IDA)}

The use of SS-IDA for the absolute quantification of a metalloprotein $(\mathrm{Cu}, \mathrm{Zn}-\mathrm{SOD})$ applying non-denaturing PAGE combined with LA-ICP-MS was reported for the first time by Deitrich et al. ${ }^{34}$ This strategy consisted in using the intrinsic metals of a metalloprotein $(\mathrm{Cu}, \mathrm{Zn}-\mathrm{SOD})$ for labeling an isotopically enriched derivate $\left({ }^{65} \mathrm{Cu},{ }^{68} \mathrm{Zn}\right.$-SOD) to be employed as a tracer for the determination of this enzyme. For complex biological samples, it was proposed that the isotopically enriched metalloprotein should be used as a spike. The authors demonstrated that it is possible to employ SS-IDA to quantify SOD separated by non-denaturing PAGE in real samples (liver cytosol), although the estimated detection limits achieved were not satisfactory and require improvement. This can be achieved by altering sample preparation methods and/or using gradient gels that can provide better resolution.

The use of an isotopically enriched metalloprotein tracer and the possible application of isotope dilution technique analysis ${ }^{9}$ would be ideal for use with LA-ICP-MS, since it is a direct calibration method, and only one parameter, the isotopic ratio, has to be measured and this can be done with high accuracy. SS-IDA is a promising technique for quantification of a particular metalloprotein in a biological system and it can be useful for the determination of disease biomarkers already described. However, an isotopically enriched derivate has to be prepared and characterized for each protein of interest, making the application of this methodology time-consuming. It is also important to point out that since the metal-protein binding strength is different for all proteins containing metals, the concept of SS-IDA developed for SOD cannot be merely extrapolated to other metalloproteins without previous analysis concerning stability and behavior during PAGE of the isotopically enriched protein. An optimization study for each protein of interest is therefore indispensable, so that this quantification strategy must be regarded as time-consuming and not applicable for the simultaneous determination of different elements/proteins in a biological sample, although it is a highly accurate strategy.

\subsection{Chemical labeling}

A very promising approach for protein quantification (including metalloproteins and metal-binding proteins) is labeling with lanthanides complexed by chelating agents that have been covalently bound to proteins via selected reaction chemistry. ${ }^{35}$ In other words, a chelate can bind a metal (lanthanide) and it is usually prepared with a reactive site or a linker molecule, which binds to the biomolecule of interest (protein, peptide, antibody). ${ }^{7}$

The metal coded tagging (MeCAT) technique consists in the attachment of a lanthanide-harboring metal tag, i.e., a macrocyclic metal chelate complex (1,4,7,10-tetraazacyclododecane1,4,7,10-tetraacetic acid (DOTA)) loaded with different lanthanides (metal (III) ions), to the cysteine residues of proteins or peptides. It is suitable for further absolute quantification of proteins via ICP-MS by using an external standard or for relative quantification via "proteomics-standard" mass spectrometric methods (e.g., MALDI-, ESI- or FTICR-MS) ${ }^{36}$ Another advantage of the MeCAT technique is that it can allow the analysis of any kind of protein or peptide by ICP-MS, and is not restricted to (metallo)proteins containing natural bound elements. In the pioneering work describing an application of MeCAT, ${ }^{37}$ SDS-PAGE and soluble 2-D gels (DPAGE) were used to separate proteins before their identification/ quantification as a solution by ICP-MS. To the best of our knowledge, this technique has not yet been applied for the analysis of proteins using PAGE combined with LA-ICP-MS methodology, 
and is thus proposed as a strategy to attain faster and more reliable quantitative results.

Using the labeling of antibodies technique, Waentig et ${ }^{28}{ }^{28}$ demonstrated that PAGE combined with LA-ICP-MS methodology can be applied in a Western blot procedure. To that end, three protein standards were first separated by SDS-PAGE and electroblotted onto NC membranes. After the immune-reaction with antibodies (labeled with $p$-SCNBn-DOTA lanthanide chelates), the element label was detected by LA-ICP-MS directly on the Western blot membrane. The sensitivity achieved was comparable to the conventional chemiluminescence detection method. Moreover, this method has the advantages of being less time-consuming and offering multiplexing capabilities that can allow the simultaneous detection of different antigens. Therefore, such a technique displays considerable potential for application in the quantification of proteins from complex biological samples.

In the literature, another type of chemical labeling is also described, using nanoparticles containing heavy metal. As there are only a few and relatively old references employing such methodology (see ref. 35), they will not be discussed here.

In summary, chemical labeling strategies can be applied for the quantification of any kind of protein before separation by denaturing PAGE and detection by ICP-MS. This is particularly important in the case of the analysis of metalloproteins and metal-binding proteins, because they can be separated with high resolution by denaturing PAGE techniques without being restricted to considering only the analysis of metals bound covalently (occurring naturally) to the proteins.

\section{Conclusions and outlook}

PAGE combined with LA-ICP-MS methodology has proven to be a suitable methodology for application in metallo(proteo)mics. Several works describe the main limitations of this strategy and attempts are being made to solve or minimize them. In this review, the limitations concerning the preservation of the integrity of metal-protein bond and contamination were described and proposed solutions were identified and compared, so that a decision may be reached about the best experimental alternative, depending on the focus of research.

The most recently proposed and most promising strategies for absolute quantification of (metallo)proteins were also discussed. They are based on species-specific isotope dilution analysis (SS-IDA) and chemical labeling. The first approach is highly accurate, but it has the limitations of requiring the preparation and characterization of an isotopically enriched derivate for each protein of interest as well as a whole optimization study for each analyte, and is therefore timeconsuming and not applicable to the determination of multiple elements/proteins in a biological sample. The second quantification strategy described is very sensitive and has the advantages of being less time-consuming and offering multiplexing capabilities permitting the simultaneous detection of different elements/ proteins, although applications to biological samples have not yet been described.

A challenging task is to establish elemental mass spectrometry (i.e., ICP-MS) as a complementary tool to be used in conjunction with molecular (MALDI-, ESI-, FTICR-) MS amongst the proteomics community. ICP-MS generates absolute quantitative elemental information while molecular MS provides protein identification that is required for quantification strategies when using natural element tags or chemical labeling strategies and, most importantly, for the interpretation of metalloproteomics data.

Many attempts have been made to develop and/or optimize techniques applied for the analysis of standard (metallo)proteins, although only a few authors actually apply them to complex biological samples. The time is ripe for metallomics to start being used for research in the life sciences (such as proteomics), since the research field was first described about ten years ago. ${ }^{38,39}$ If this does not happen soon, it will remain a research field known only to analytical chemists.

Both basic and applied science (chemistry, biology, biochemistry, medicine, pharmacology, among others) are essential for an examination of questions related to metals and proteins, each from its own perspective. Therefore, only multidisciplinary approaches can elucidate various points of view on a problem, thus providing more conclusive answers.

\section{Acknowledgements}

A.S. would like to thank the Alexander von Humboldt Foundation (Bonn, Germany) for the postdoctoral fellowship.

\section{References}

1 L. Banci, Curr. Opin. Chem. Biol., 2003, 7, 143-149.

2 M. A. O. da Silva, A. Sussulini and M. A. Z. Arruda, Expert Rev. Proteomics, 2010, 7, 387-400 and references therein.

3 J. Szpunar, Anal. Bioanal. Chem., 2004, 378, 54-56.

4 J. Szpunar, Analyst, 2005, 130, 442-465.

5 Z. Qin, B. Lai, A. Matusch, J. S. Becker and J. Caruso, Metallomics, $2011,3,28-37$.

6 R. Łobiński, J. S. Becker H. Haraguchi and B. Sarkar, Pure Appl. Chem., 2010, 82, 493-504 and references therein.

7 J. S. Becker and N. Jakubowski, Chem. Soc. Rev., 2009, 38, 1969-1983.

8 R. Ma, C. W. McLeod, K. Tomlinson and R. K. Poole, Electrophoresis, 2004, 25, 2469-2477.

9 J. S. Becker, Inorganic Mass Spectrometry Principles and Applications, John Wiley \& Sons, Chichester, 2007 and references therein.

10 J. S. Becker and D. Salber, TrAC, Trends Anal. Chem. (Pers. Ed.), 2010, 29, 966-978.

11 J. S. Becker, M. Zoriy, A. Matusch, B. Wu, D. Salber, C. Palm and J. Su. Becker, Mass Spectrom. Rev., 2010, 29, 156-175 and references therein.

12 J. S. Becker, A. Matusch, J. Su. Becker, B. Wu, C. Palm, A. J. Becker and D. Salber, Int. J. Mass Spectrom, 2011, 307, 3-15.

13 M. S. Jiménez, L. Rodriguez, M. T. Gomez and J. Castillo, Talanta, 2010, 81, 241-247.

14 Trends in Sample Preparation, ed. M. A. Z. Arruda, Nova Science, New York, 2007.

15 A. Raab, B. Pioselli, C. Munro, J. Thomas-Oates and J. Feldmann, Electrophoresis, 2009, 30, 303-314.

16 A. Sanz-Medel, M. Montes-Bayón, M. R. F. de la Campa, J. R. Encinar and J. Bettmer, Anal. Bioanal. Chem., 2008, 390, 3-16.

17 L. Tastet, D. Schaumlöffel and R. Łobiński, J. Anal. At. Spectrom., 2008, 23, 309-317.

18 J. Su. Becker, M. Zoriy, V. L. Dressler, B. Wu and J. S. Becker, Pure Appl. Chem., 2008, 80, 2643-2655.

19 S. F. Durrant and N. I. Ward, J. Anal. At. Spectrom., 2005, 20, 821-829.

20 S. Mounicou and R. Łobiński, Pure Appl. Chem., 2008, 80, $2565-2575$. 
21 M. González-Fernández, T. García-Barrera, A. Arias-Borrego, J. Jurado, C. Pueyo, J. López-Barea and J. L. Gómez-Ariza, Biochimie, 2009, 91, 1311-1317.

22 J. Su. Becker, R. Łobiński and J. S. Becker, Metallomics, 2009, 1, 312-316.

23 B. Wu, Y. Chen and J. S. Becker, Anal. Chim. Acta, 2009, 633, $165-172$.

24 A. Sussulini, H. Kratzin, O. Jahn, C. E. M. Banzato, M. A. Z. Arruda and J. S. Becker, Anal. Chem., 2010, 82, 5859-5864.

25 C. C. Chery, L. Moens, R. Cornelis and L. Vanhaecke, Pure Appl. Chem., 2006, 78, 91-103.

26 J. Su. Becker, S. Mounicou, M. Zoriy, J. S. Becker and R. Łobiński, Talanta, 2008, 76, 1183-1188.

27 J. Su. Becker, M. Zoriy, C. Pickhardt, M. Przybylski and J. S. Becker, Int. J. Mass Spectrom., 2005, 242, 135-144.

28 L. Waentig, P. H. Roos and N. Jakubowski, J. Anal. At. Spectrom., 2009, 24, 924-933.

29 W. Brüchert and J. Bettmer, Anal. Chem., 2005, 77, 5072-5075.

30 V. L. Elliott, C. W. McLeod and P. S. Marshall, Anal. Bioanal. Chem., 2005, 383, 416-423.

31 G. Ballihaut, L. E. Kilpatrick, E. L. Kilpatrick and W. C. Davis, J. Anal. At. Spectrom., 2011, 26, 383-394.

32 M. Wind, I. Feldmann, N. Jakubowski and W. D. Lehmann, Electrophoresis, 2003, 24, 1276-1280.

33 D. Pozebon, V. L. Dressler, M. F. Mesko, A. Matusch and J. S. Becker, J. Anal. At. Spectrom., 2010, 25, 1739-1744.

34 C. L. Deitrich, S. Braukmann, A. Raab, C. Munro, B. Pioselli, E. M. Krupp, J. E. Thomas-Oates and J. Feldmann, Anal. Bioanal. Chem., 2010, 397, 3515-3524.
35 A. Prange and D. Pröfrock, J. Anal. At. Spectrom., 2008, 23, 432-459 and references therein.

36 R. Ahrends, S. Pieper, B. Neumann, C. Scheler and M. W. Linscheid, Anal. Chem., 2009, 81, 2176-2184.

37 R. Ahrends, S. Pieper, A. Kühn, H. Weisshoff, M. Hamester, T. Lindemann, C. Scheler, K. Lehmann, K. Taubner and M. W. Linscheid, Mol. Cell. Proteomics, 2007, 6, 1907-1916.

38 R. J. P. Williams, Coord. Chem. Rev., 2001, 216-217, 583-595.

39 H. Haraguchi, J. Anal. At. Spectrom., 2004, 19, 5-14.

40 J. Su. Becker, D. Pozebon, A. Matusch, V. L. Dressler and J. S. Becker, Int. J. Mass Spectrom., 2011, 307, 66-69.

41 Z. Pedrero, S. Murillo, C. Cámara, E. Schram, J. B. Luten, I. Feldmann, N. Jakubowski and Y. Madrid, J. Anal. At. Spectrom., 2011, 26, 116-125.

42 B. Wu, I. Susnea, Y. Chen, M. Przybylski and J. S. Becker, Int. J. Mass Spectrom., 2011, 307, 85-91.

43 J. S. Becker, S. F. Boulyga, J. Su. Becker, C. Pickhardt, E. Damoc and M. Przybylski, Int. J. Mass Spectrom., 2003, 228, 985-997.

44 S. Frelon, O. Guipaud, S. Mounicou, R. Łobiński, O. Delissen and F. Paquet, Radiochim. Acta, 2009, 97, 367-373.

45 U. Krause-Buchholz, J. S. Becker, M. Zoriy, C. Pickhardt, M. Przybylski and G. Rödel, Int. J. Mass Spectrom., 2006, 248, 56-60.

46 M. R. B. Binet, R. Ma, C. W. McLeod and R. K. Poole, Anal. Biochem., 2003, 318, 30-38.

47 J. Su. Becker, M. Zoriy, M. Przybylski and J. S. Becker, Int. J. Mass Spectrom., 2007, 261, 68-73.

48 Thomson Reuters Web of Knowledge, v. 5.3, http://apps. webofknowledge.com/. 